Bulletin d'Histoire Contemporaine de l'Espagne

$54 \mid 2020$

Les espaces du politique dans l'Espagne du Trienio liberal (1820-1823)

\title{
Cambios y continuidades en los ayuntamientos constitucionales del Trienio liberal (1820-1823)
}

Changements et continuités dans les municipalités constitutionnelles du Trienio Liberal (1820-1823)

Changes and Continuities in the Constitutional Municipalities of Trienio

Liberal (1820-1823)

\section{Ramon Arnabat Mata}

\section{OpenEdition Journals}

\section{Edición electrónica}

URL: http://journals.openedition.org/bhce/2691

DOI: 10.4000/bhce.2691

ISSN: 1968-3723

Editor

Presses Universitaires de Provence

Edición impresa

Fecha de publicación: 1 enero 2020

ISSN: 0987-4135

\section{Referencia electrónica}

Ramon Arnabat Mata, « Cambios y continuidades en los ayuntamientos constitucionales del Trienio liberal (1820-1823) », Bulletin d'Histoire Contemporaine de l'Espagne [En línea], 54 | 2020, Publicado el 01 julio 2020, consultado el 30 diciembre 2020. URL : http://journals.openedition.org/bhce/2691 ; DOI : https://doi.org/10.4000/bhce.2691

Este documento fue generado automáticamente el 30 diciembre 2020.

Bulletin d'histoire contemporaine de l'Espagne 


\section{Cambios y continuidades en los ayuntamientos constitucionales del Trienio liberal (1820-1823)}

Changements et continuités dans les municipalités constitutionnelles du Trienio Liberal (1820-1823) Changes and Continuities in the Constitutional Municipalities of Trienio Liberal (1820-1823)

Ramon Arnabat Mata

\section{Los ayuntamientos constitucionales}

Durante el Trienio Liberal (1820-1823) se pusieron en marcha de forma sistemática los ayuntamientos constitucionales que se convirtieron en una pieza clave del engranaje del nuevo régimen liberal y en uno de los espacios de confrontación entre los diferentes sectores del liberalismo y entre ambos y el realismo ${ }^{1}$.

2 En el seno del liberalismo español se produjo un agrio debate sobre las competencias, el grado de autonomía y el modo de financiación de los ayuntamientos. Este debate se inició en las Cortes de Cádiz y continuó durante el Trienio Liberal, aunque, como señala Adolfo Posada, las Cortes del Trienio no se limitaron «a resucitar la obra de las Cortes de Cádiz.» y, aunque mantuvieron los principios constitucionales de la Constitución de 1812 , acentuaron «sus principales rasgos y rectificando algunos otros en cierto sentido descentralizador $»^{2}$.

3 Los jefes políticos y las diputaciones tenían una visión muy diferente del papel de los ayuntamientos. El mes de mayo de 1820, el jefe político de Catalunya, Josep Castellar, dirigió una Instrucción a los ayuntamientos catalanes conminándoles a situarse bajo su tutela ${ }^{3}$. Un año más tarde, el 17 de abril de 1821, la Diputación de Catalunya dirigió un manifiesto a las Cortes solicitando la reforma de la Ley de 23 de junio de 1813 y la elaboración de una nueva ley de régimen local que delimitara mejor las funciones de 
cada uno de los organismos locales y provinciales, reforzando el papel de los ayuntamientos y de las diputaciones en detrimento del poder del jefe político en la política local:

Se condolió al ver que los Ayuntamientos, esas corporaciones tutelares de los pueblos y de las que es la cabeza y el alma, por decirlo así, la Diputación, no podían hacer llegar hasta a ella en derechura sus acentos, ni tampoco recibir sus disposiciones sino por el conducto de un agente del Gobierno, que por la naturaleza de su destino y por el carácter que representa, tiene muy pocos puntos de contacto con unas autoridades enteramente populares ${ }^{4}$.

4 En el mismo sentido se dirigieron a las Cortes las diputaciones de Madrid y de Vizcaya. La respuesta de las Cortes no llegó hasta el Decreto de 3 de febrero de 1823 que, a la vez que delimitaba las funciones del alcalde y del jefe político, ponía al primero bajo una estricta dependencia del segundo: «el gobierno político de los pueblos está a cargo del Alcalde o Alcaldes de ellos, bajo la inspección del Jefe político superior de la provincia» ${ }^{5}$. Como señala Manel Risques, la Instrucción de 1823 «perfeccionaba el sistema definido el 1813, pero en absoluto alteraba la organización o el funcionamiento, [...], en todo caso limaba la capacidad de intervención de la autoridad política superior y ampliaba las atribuciones propias de las corporaciones con el objetivo de lograr una mejora de la acción administrativa» ${ }^{6}$. En definitiva, se trataba de encajar los ayuntamientos en la estructura del estado liberal, limitando su autonomía, la económica a manos de las diputaciones provinciales y la política a manos del jefe político.

5 El liberalismo moderado siempre miró con recelo a los ayuntamientos y, en cambio, dotó de protagonismo y competencias a los jefes políticos, mientras que las diputaciones quedaban a medio camino de unos y otros. Lo cual fue criticado por la Comisión que analizaba la Memoria presentada por el Secretario de Gobernación José $\mathrm{M}^{\mathrm{a}}$ Moscoso a las Cortes:

Tiene poco cariño a los Ayuntamientos, únicas corporaciones subalternas verdaderamente populares; pues las Diputaciones de Provincias que también lo son, tienen por miembro principal al Gefe Político hechura del Gobierno. [...] De otro modo son mirados los Gefes Políticos, estos siempre son loables [...] Se diría (según se explica en la Memoria) que no hay Gefe Político malo, ni Ayuntamiento bueno7.

6 A pesar de las diversas opiniones sobre el papel de los ayuntamientos, la propaganda liberal insistió siempre en la importancia de las instituciones municipales y de las tareas que realizaban. Tenemos un ejemplo en el Coloqui entre un rector $i$ un pagès anomenat Macari, en el que se destacaba el importante papel que debían jugar los ayuntamientos - «la más sabia de las instituciones»- en la configuración del nuevo sistema constitucional, a la vez que se animaba a los ciudadanos a participar en las elecciones municipales. Se destacaba, también, la importancia de la elección popular de alcaldes y regidores: "porque el Pueblo nunca se equivoca en elegir a los mejores»; y ello era necesario para acabar con el «círculo vicioso» de los privilegios y vinculaciones de los cargos públicos que «tiranizando a los Pueblos se chapaban los tesoros, cometiendo dos mil estafas, sin dar cuenta ni razón» ${ }^{8}$. 


\section{Las elecciones municipales}

7 Uno de los tres primeros decretos que, a propuesta de la Junta Provisional, firmó el Rey el 9 de octubre de 1820 fue el de la inmediata convocatoria de elecciones municipales. Las elecciones de los nuevos consistorios constitucionales se realizaron durante la segunda quincena del mes marzo y el mes de abril, mediante un sistema de sufragio universal masculino indirecto en el que podían participar todos los vecinos cabezas de familia mayores de 25 años.

No faltaron voces que, pasados los primeros meses, solicitaran el sufragio censitario. Por ejemplo José de Churruca planteaba la necesidad de «que se limite el nombramiento de electores y capitulares de Ayuntamientos a los ciudadanos que paguen una cuota de contribución directa sobre la propiedad raíz, o sobre otros capitales y productos de cualquier origen», aunque «atemperándose esta graduación a las circunstancias en que se hallen las respectivas provincias y pueblos de la Monarquía» ${ }^{1}$. Una reivindicación claramente destinada a asegurar el poder de las clases dominantes locales y que será recogida por los liberales moderados². Pero también hubo quejas de jóvenes menores de 25 años que querían participar en les elecciones ya que entendían que el límite de edad se establecía para ser elegido y no para votar ${ }^{3}$.

El proceso electoral constaba de dos niveles. Primero los vecinos se reunían por parroquias y elegían a los electores parroquiales quienes, junto a los otros electores parroquiales del municipio, escogían a los alcaldes y a los regidores. En las elecciones parroquiales se dirimían muchos de los conflictos políticos y sociales presentes en los municipios y por ello, tanto la administración como las sociedades, animaban a los ciudadanos a participar. Nos sirve de muestra el escrito de la Sociedad Patriótica barcelonesa llamando a la ciudadanía a elegir con acierto por el bien de la ciudad: Sin dar entrada a las intrigas, sin oír a los que intentasen captar vuestros votos, meditad en el centro de vuestras familias cuales han de ser vuestros elegidos. Más no lo sean jamás, oh Catalanes, no sean de ningún modo vuestros elegidos los que pretendieren serlo. Séanlo los hombres de bien que no buscan los empleos, o los puestos de gobierno en vuestros pueblos; aquellos que mejor gobiernen sus familias ${ }^{4}$.

Las elecciones municipales no estuvieron exentas de agrias polémicas, lo que demuestra el interés que despertaron, tanto entre los vecinos, como entre los diversos sectores políticos ${ }^{5}$. Por ejemplo, se denunció cohecho en las elecciones celebradas en la parroquia barcelonesa de Santa María y del Pino:

El cohecho, la intriga y el egoísmo erigieron su morada en el salón de la Lonja y colegio Tridentino: muchas personas sin entender la formalidad del acto se acercaban a la mesa sin saber a que persona tenían que dar el voto, otros hacían circular listas con el nombre de electores que habían de elegirse, y lo peor de todo es, que muchos ciudadanos sinceros, buenos e imparciales que solamente se habían dirigido a la junta para cooperar a la grande obra de la felicidad de la patria con la intención de dar el voto a personas capaces para el desempeño de tan grande encargo, se fueron sin dar voto, viendo la confusión que reinaba. Muchas notas circularon en estas dos convocatorias unas en que se comprendían los ciudadanos más beneméritos, y otras llenas de egoístas y gente superficial ${ }^{6}$. 


\section{La participación electoral}

11 Una parte considerable de la ciudadanía no se vio interpelada por las llamadas a la participación y las convocatorias para elegir electores parroquiales no fueron muy concurridas. En la ciudad de Reus tenían derecho a voto unos 4.500 hombres, pero solo 527 (el 12\%) participaron en las primeras elecciones parroquiales de finales de marzo de 1820. A finales de 1820, en la elección de los electores que debían elegir a la mitad del consistorio que debía renovarse para el año 1821, tan solo participaron 278 personas (un 6\%), la mitad de los que lo habían hecho en marzo de este mismo año. En las elecciones del mes de diciembre de 1821 para elegir a la mitad de regidores que debían renovarse para el año 1822, participaron 491 vecinos (un 11\%) y se volvía a las cifras de dos años antes, ahora coincidiendo con la agudización de los enfrentamientos entre liberales moderados y exaltados ${ }^{1}$.

12 En la ciudad de Tarragona tenían derecho a voto unos 2.000 vecinos y 634 de ellos (un 32\%) participaron en las elecciones municipales de marzo de 1820. En las elecciones de finales de 1820 para renovar la mitad del consistorio para el año 1821, participaron 426 vecinos (un 21\%). En las elecciones de compromisarios municipales para la elección de Diputados, participaron 660 vecinos (un 33\%) ${ }^{2}$. En Tarragona, pues, la participación electoral de los vecinos en las elecciones se situaba entre el $20 \%$ y el $35 \%$ y ello a pesar de que el ayuntamiento de la ciudad insistió una y otra vez en la importancia de la participación electoral de los ciudadanos:

El Ayuntamiento no puede menos de advertiros que vuestro bien o vuestro mal dependerá de la buena o mala elección que hagáis. Usad pues de este derecho inapreciable que la Constitución os concede para que seáis bien gobernados protegidos $\mathrm{y}$ asistidos. No haya uno de vosotros que deje de concurrir a dar su voto, porque la omisión o la indiferencia en esta y semejantes elecciones causaría vuestra perdición ${ }^{3}$.

En Granollers participaban en las elecciones municipales una media de 150 vecinos sobre un total de 315 (el 48\%), en cambio para elegir una comisión que debía discutir sobre los impuestos asistieron cerca de 200 vecinos (el 64\%) ${ }^{4}$. En las elecciones parroquiales de Lleida del mes de diciembre de 1822 participaron 966 vecinos de los 2.028 que podían hacerlo (un $48 \%)^{5}$. En estas dos ciudades se dieron porcentajes de participación electoral más elevados que la media catalana y ello, seguramente, se debe a la profunda división entre liberales y realistas, ya que ello obligó a ambos bandos a movilizar electoralmente a sus seguidores. Lo cual originó diversos conflictos electorales. En Lleida, por ejemplo, hubo quejas porque no se dejó votar a los militares en una ocasión, y en otra porque alguien intentó sobornar a tres electores proponiéndoles cobrar dos pesetas si votaban por un determinado candidato a alcalde.

\section{Aproximación socio-profesional a los ayuntamientos constitucionales}

Los resultados del estudio que hemos realizado de los alcaldes y regidores de diez municipios del Penedès durante este período nos muestran que un $25,5 \%$ eran hacendados, un $20,5 \%$ comerciantes, un $17 \%$ artesanos y menestrales, un $13 \%$ campesinos, un $12 \%$ profesionales liberales, un $6 \%$ fabricantes, un $5 \%$ tenderos y un $1 \%$ aparceros $^{1}$. En los consistorios constitucionales de Girona (5.730 h.) encontramos un 
$36 \%$ de hacendados, un $36 \%$ de profesiones liberales, un $24 \%$ de artesanos y menestrales y un $3 \%$ de nobles (destacando la ausencia de comerciantes) ${ }^{2}$. En el ayuntamiento de Mataró (9.200 h.), los cargos municipales fueron ocupados por comerciantes (un 40\%), hacendados (20\%), abogados (15\%) y otras profesiones liberales $(12 \%)^{3}$. En el de Lleida $\left(10.140\right.$ h.) por hacendados $(40 \%)$, profesionales liberales $(40 \%)$ y comerciantes $(20 \%)^{4}$. En l'Hospitalet de Llobregat (1.095 h.) la mayoría de los regidores eran propietarios ; y lo mismo sucedió en Sant Cugat del Vallès $\left(1.145\right.$ h.) ${ }^{6}$.

Los ayuntamientos constitucionales de Arenys de Mar (4.035) estuvieron formados por hacendados (30\%), comerciantes (30\%), pilotos de marina (20\%) y funcionarios $(20 \%)^{7}$; y los de Esparreguera $(2.000$ h.) por campesinos acomodados, fabricantes de trapos, notarios y algún menestral ${ }^{8}$. En el consistorio de Vic $(9.190$ h.) tuvieron una presencia destacada los hacendados, los artesanos y menestrales y los comerciantes y tenderos 9 . En Granollers (1.575 h.) un $41 \%$ de los alcaldes y regidores eran artesanos y menestrales, un $23 \%$ comerciantes, un $12 \%$ hacendados, un $12 \%$ profesiones liberales, un $6 \%$ campesinos y otro $6 \%$ militares retirados ${ }^{10}$.

En los ayuntamientos constitucionales de la ciudad de Reus $(16.140$ h.) destaca la presencia de los comerciantes, que representan el $41 \%$ del total de alcaldes y regidores. Seguidos de los hacendados y de los profesionales liberales con un $18 \%$ cada uno y de los artesanos y menestrales con el $17 \%$. Con poca presencia encontramos a los fabricantes con el $4 \%$ y los tejedores con el $1 \%^{11}$. En los consistorios constitucionales Tarragona (7.320 h.), encontramos los mismos grupos sociales: hacendados, profesionales liberales, comerciantes, funcionarios y algún campesino ${ }^{12}$.

Los regidores y alcaldes de la ciudad de Barcelona (94.380 h.) durante el Trienio son hacendados (29\%), profesionales liberales $(17,5 \%)$, artesanos y menestrales $(15,5 \%)$, comerciantes $(14,5 \%)$, fabricantes $(10,5 \%)$, nobles $(7,5 \%)$ y militares $(5,5 \%)^{13}$. Eliseu Toscas afirma que, en Barcelona, los grupos sociales que ocupan las regidorías, la oficialidad de la Milicia Nacional Voluntaria y la adquisición de bienes desamortizados configuran una amalgama nobiliario-burguesa que domina el poder político local durante el Trienio ${ }^{14}$. Esto es cierto sobre todo para los primeros años (1820 y 1821), pero, al igual que sucede en otras ciudades catalanas, a medida que avanza el proceso revolucionario (1822 y 1823) se reduce el número de regidores pertenecientes a los sectores más acomodados: los nobles pasan del $10 \%$ al $0 \%$ y los hacendados del $25 \%$ al $8 \%$. Al tiempo que aumenta la presencia de los sectores intermedios: los comerciantes pasan del $10 \%$ al $17 \%$, los fabricantes del $10 \%$ al $21 \%$, los abogados del $15 \%$ al $25 \%$ y los militares del 0 al $8 \%$. Y se mantienen los artesanos y menestrales que pasan del $25 \%$ al $21 \%$. Con todo, los únicos colectivos que están proporcionalmente representados en el ayuntamiento de la ciudad respecto a su peso socioeconómico son los artesanos y menestrales y los nobles.

18 En la ciudad de Valencia destaca el peso de los abogados (30\%) y de los comerciantes (34\%), seguidos de los militares (9\%), campesinos (6\%), artesanos (6\%), profesionales liberales (6\%), propietarios (4\%), funcionarios $(4 \%)$ y fabricantes $(2 \%)^{15}$. Y en Castellón, los campesinos (24\%), los profesionales liberales (21\%), los hacendados $(21 \%)$ y los menestrales (21\%) ocupan la mayoría de los cargos municipales ${ }^{16}$. En el Ayuntamiento de Mallorca se produce un «desplazamiento de un sector de aristócratas o hacendados a favor de un nuevo grupo de hacendados, pero que tenían más inquietudes comerciales» ${ }^{17}$. En Santander y en Logroño el poder político local estará controlado por la burguesía mercantil de estas ciudades ${ }^{18}$. En Salamanca, comerciantes, propietarios y 
personas de la Universidad controlaban el Ayuntamiento ${ }^{19}$. En Galicia también los hacendados también tuvieron un importante papel en la vida política local, al convertirse «la propiedad, y ya no el privilegio, [...] en el trampolín de acceso al poder local institucionalizado $»^{20}$. Aspectos que, con matices, se repiten en Fernán Núñez o en Segovia ${ }^{21}$. Para el conjunto de España, Juan Francisco Fuentes señala la presencia destacada en los ayuntamientos liberales del Trienio de los hacendados, comerciantes y menestrales ${ }^{22}$. Estas características sociales del poder político local en España no son muy diferentes a las de Francia entre 1789 y 1840: un 30\% de los cargos municipales eran hacendados, un 30\% campesinos medianos, un $9 \%$ propietarios, un $8 \%$ de comerciantes y un $6 \%$ menestrales $^{23}$. Por ello Jean-Pierre Jessenne destaca la importancia de los campesinos acomodados, los fermiers, en el poder local francés, hasta el punto de hablar de fermocratie, porqué ya ostentaban parcelas importantes del poder local antes de la revolución y con esta lo reafirman ${ }^{24}$.

\section{Aproximación socio-profesional a los electores parroquiales}

19 Si ampliamos el análisis socio-profesional a los electores parroquiales, aquellos a quienes directamente elegían los vecinos en las juntas parroquiales y municipales, veremos cómo, con pequeñas excepciones, se repiten las mismas características del personal político local. En la ciudad de Barcelona un 32\% de los electores eran profesionales liberales (básicamente abogados), un $28 \%$ comerciantes, un $12 \%$ artesanos y menestrales, un $10 \%$ hacendados, un $2 \%$ nobles y un $2 \%$ militares $^{1}$.

20 En la ciudad de Reus, un $34 \%$ de los electores parroquiales eran comerciantes, un $32 \%$ artesanos y menestrales, un $14 \%$ profesionales liberales, un $12 \%$ tejedores, un $4 \%$ fabricantes, un $3 \%$ hacendados y un $1 \%$ jornaleros $^{2}$. En Tarragona los hacendados monopolizan esta representación con un $47 \%$ y, a su lado, encontramos campesinos, menestrales, profesionales liberales, marineros y clero ${ }^{3}$. En Girona, el $24 \%$ de los electores eran artesanos y menestrales, el $23 \%$ eclesiásticos y el $13 \%$ abogados, hacendados y nobles ${ }^{4}$. En Lérida, un $40 \%$ eran eclesiásticos, un $20 \%$ propietarios y otro $20 \%$ hacendados, un $13 \%$ artesanos y menestrales y un $7 \%$ comerciantes $^{5}$. En Granollers, el $22 \%$ eran comerciantes, el 17,5\% profesiones liberales, el 17,5\% campesinos, el $13 \%$ artesanos y menestrales, el 13\% miembros del clero, el 8,5\% funcionarios y el $8,5 \%$ militares retirados ${ }^{6}$. En Torroella de Montgrí ( $2895 \mathrm{~h}$.) los electores parroquiales fueron el cura párroco, tres hacendados, dos comerciantes y tres menestrales ${ }^{7}$.

21 La composición social de los electores parroquiales varía, naturalmente, según las características socioeconómicas del municipio y su orientación política más decantada al liberalismo o al realismo. Por ejemplo, destaca la presencia de eclesiásticos entre los electores parroquiales en ciudades donde el realismo y el moderantismo liberal tienen una presencia importante, cómo Lérida (el $40 \%$ del total), Girona (23\%) o en el partido de Granollers $(24 \%)^{8}$. Presencia que se reduce significativamente en aquellas ciudades más liberales y donde el liberalismo exaltado tiene más fuerza, cómo en los casos de Reus, donde no se eligió ninguno, o de Barcelona donde solo representaban el 3\%. En cambio, los hacendados y los profesionales liberales tienen una presencia más regular entre los electores en la mayoría de los municipios. Mientras que los comerciantes y los artesanos y menestrales tienen porcentajes más elevados entre los electores parroquiales en las ciudades medianas y grandes (Barcelona, Reus, Girona o Granollers), 
destacando que la presencia de artesanos y menestrales es más importante en los municipios menos liberales y menos exaltados (Tarragona, Girona o Lleida).

Finalmente, señalemos que la presencia de las clases trabajadoras y del campesinado entre los electores es muy reducida tanto porcentualmente, como geográficamente (Reus o Granollers). En cualquier caso, la presencia de las clases medias y trabajadoras es más importante entre los electores parroquiales que entre los alcaldes y regidores donde predominan las clases acomodadas.

\section{Poder político y poder económico}

La denominación de un oficio o de una categoría económica, que es lo que nos ofrecen las fuentes consultadas, nos orientan, pero son excesivamente genéricas para afinar más porque, por ejemplo, no es lo mismo ser comerciante en Barcelona que en un pequeño pueblo. Pero, vamos a intentar precisar un poco más comparando las categorías socio profesionales de los alcaldes y regidores de los ayuntamientos constitucionales y su representatividad social. En el Penedès, los hacendados, los comerciantes y los profesionales liberales que ocupan el 58\% de los cargos municipales, tan solo representan un $5 \%$ de la población activa masculina; mientras que los menestrales y los fabricantes obtienen una representación política del $23 \%$ más equilibrada con su peso social (15\%); en cambio, los campesinos que representan las dos terceras partes de la sociedad, tan solo ocupan una quinta parte de los cargos municipales $\mathrm{y}$, aún, dentro del campesinado es el sector más acomodado y mediano el que ocupa estos cargos (13\%), cuando solo representa un $20 \%$ de la población. Así, las clases trabajadoras del campo y de la ciudad (jornaleros, pequeños campesinos, trabajadores) que representan la mitad de la población activa masculina, tan solo ocupan el $1 \%$ de los cargos municipales.

En algunos casos hemos podido cruzar los datos de los ayuntamientos constitucionales con los datos fiscales. En Sant Sadurní d'Anoia (1 335 h.), por ejemplo, los pequeños contribuyentes que representan el $64,4 \%$ de los vecinos, tan solo ocupan el $33,5 \%$ de los cargos municipales; y los pequeños-medianos contribuyentes que representan el $26,1 \%$ de los vecinos, ocupan el 9,5\% de los cargos municipales; mientras que los más ricos de la villa (medianos, medianos-grandes y grandes contribuyentes) que representan el 9,5\% de los vecinos, ocupan el 57\% de los cargos municipales ${ }^{1}$.

En Tarragona hemos realizado otra aproximación a partir del reparto de una contribución extraordinaria sobre las clases acomodadas de la ciudad: 272 personas que representaban el $13 \%$ de los vecinos. El 57\% de los electores parroquiales y el $68 \%$ de les regidores municipales pertenecían a este colectivo, siendo el $87 \%$ restante de vecinos el $43 \%$ de los electores parroquiales y el $32 \%$ de los cargos municipales. Los grandes propietarios, que representaban el $9 \%$ del total de propietarios y el $1 \%$ de los vecinos, ocuparon el $14 \%$ de las regidurías y fueron el $17 \%$ de los electores parroquiales, lo cual indica que casi uno de cada cinco fue regidor y elector. Los medianos propietarios, que representaban el $2 \%$ de los vecinos, ocuparon el $17 \%$ de cargos consistoriales y fueron el $13 \%$ de los electores. En cambio, los pequeños propietarios, que representaban un $10 \%$ de los vecinos, ocuparon el $41 \%$ de las regidurías y el $35 \%$ de los electores.

En la ciudad de Girona el cruce de los datos de los regidores constitucionales con los que nos ofrece el padrón de 1824, nos muestra que los hacendados y los profesionales liberales que ocupan el $72 \%$ de los cargos municipales tan solo representan el $12 \%$ de 
los vecinos de la ciudad, mientras que artesanos y menestrales obtienen una representación inferior a su peso social que era casi del 50\%; y quedando excluidos del poder municipal los jornaleros y los campesinos que representaban una cuarta parte de la sociedad gerundense ${ }^{2}$.

\section{Cambios y continuidades}

Vamos ahora a aproximarnos al grado de cambio que significó la implantación de los ayuntamientos constitucionales durante el Trienio Liberal respecto de los ayuntamientos absolutistas del período anterior (1814-1819) y posterior (1824-1833). No obstante, debemos adoptar algunas prevenciones y entre ellas la de no considerar como absolutistas a todos los regidores de los ayuntamientos absolutistas y como liberales todos los regidores de los ayuntamientos constitucionales. En los ayuntamientos absolutistas hubo regidores de trayectoria liberal, de la misma manera que en los ayuntamientos constitucionales los hubo de trayectoria absolutista.

En nuestro estudio sobre los ayuntamientos del Penedès durante el período 1814-1833, constatamos cambios significativos en la composición social de unos y otros. Durante el Trienio disminuye la presencia de los campesinos y de los artesanos y menestrales respecto a los períodos absolutistas, pasando del $19 \%$ al $13 \%$ y del $28 \%$ al $17 \%$, respectivamente. En cambio, se mantiene la presencia de los profesionales liberales (del $10 \%$ al $12 \%$ ) y de los aparceros (del $1,5 \%$ al $1 \%$ ); y aumenta la presencia de hacendados (del 22\% al 25,5\%), comerciantes (del 16 al 20,5\%), tenderos (del 1,5\% al 5\%) y fabricantes (del $2 \%$ al 6\%). A modo de resumen podemos decir que los campesinos, aparceros, artesanos y menestrales y tenderos pasan de representar la mitad de los cargos municipales en los ayuntamientos absolutistas al $36 \%$ en los constitucionales; mientras que los comerciantes, profesionales liberales y fabricantes, pasan del $50 \%$ al $64 \%$.

El cambio es mucho más importante en ciudades como Barcelona y Reus o en capitales de corregimiento como Girona. En Barcelona los nobles pasan de representar el 30\% de los regidores en los ayuntamientos absolutistas al $9 \%$ en los liberales; mientras que los comerciantes y hacendados mantienen una presencia importante, alrededor del $40 \%$, en ambos ayuntamientos; en cambio, incrementan su representación en los ayuntamientos constitucionales los fabricantes que pasan del $0 \%$ al $10 \%$, los abogados del $9 \%$ al $19 \%$ y los artesanos y menestrales del $11 \%$ al $21 \%^{1}$. También en Reus se producen cambios significativos: desaparecen los nobles y los militares de los ayuntamientos constitucionales, cuando en los absolutistas representaban el 8\%; se duplica el porcentaje de comerciantes que pasa del $22 \%$ al $41 \%$; y aumenta también el de artesanos y menestrales que pasa del $11 \%$ al $17 \%$; mientras que los profesionales liberales, los hacendados, los fabricantes y los tejedores mantienen sus porcentajes (alrededor de un $42 \%$ en conjunto) ${ }^{2}$.

30 En los ayuntamientos constitucionales de la ciudad de Girona se registra una disminución del peso de los nobles, que pasan del 7\% al 3\%, y un aumento de la presencia de los hacendados, que pasan del $31 \%$ al $36 \%$ y que, prácticamente compensa el anterior. Se mantiene, en cambio, el porcentaje de los profesionales liberales (36\% frente al $34 \%$ ) y aumenta la presencia de artesanos y menestrales (24\% frente al $20 \%)^{3}$. En los ayuntamientos constitucionales de Lleida aumenta el porcentaje de campesinos, artesanos y comerciantes, en detrimento de nobles y abogados ${ }^{4}$. 
31 En los ayuntamientos constitucionales de la ciudad de València disminuye el peso de los propietarios que pasa del $41 \%$ al $4 \%$ y el de los militares (del $18 \%$ al $9 \%$ ), en cambio aumenta el peso de los abogados (del 12\% al 30\%) y el de los comerciantes (del 29\% al 34\%); y aparecen nuevos grupos sociales en el consistorio, aunque con una débil presencia: artesanos, campesinos, profesionales liberales, fabricantes y funcionarios. Durante el Trienio el consistorio pasó a manos de una burguesía integrada por abogados y hombres de negocios relacionados con la producción y comercialización de seda, desplazando a los militares y a los propietarios ${ }^{5}$. En Castelló de la Plana los menestrales y los campesinos representan un porcentaje más elevado de regidores en los ayuntamientos del Trienio que en los absolutistas ( $21 \%$ frente al $15 \%$ y $24 \%$ frente al $18 \%$, respectivamente); y lo mismo sucede con los profesionales liberales ( $21 \%$ frente al $12 \%)$. Mientras que en los ayuntamientos absolutistas predominan los hacendados que doblan su representación respecto a los constitucionales ( $44 \%$ frente al $21 \%)^{6}$.

En las comarcas catalanas controladas total o parcialmente por los realistas y alejadas de la influencia constitucional, los ayuntamientos fueron ocupados por personas próximas al realismo, pero, también, pertenecientes a les clases medias y acomodadas, tal y como hemos demostrado para el Penedès y se puede comprobar en las comarcas del interior de Catalunya y del Ebro ${ }^{7}$. El ayuntamiento de Ulldecona refleja bien esta situación. Se trata de un ayuntamiento dominado por los campesinos, sobre todo en los periodos absolutistas (63\%), pero también en el constitucional (52\%). Los hacendados mantienen el porcentaje (15\%), los profesionales liberales y los artesanos y menestrales aumentan su peso en los ayuntamientos constitucionales (19\% versus $9 \%$ y $15 \%$ versus $10 \%$, respectivamente) ${ }^{8}$.

33 El caso de Solsona es muy representativo de los ayuntamientos en las zonas realistas. En los ayuntamientos constitucionales de esta ciudad del pre-Pirineo registramos una importante presencia de elementos realistas y el control del poder político local por el colectivo de artesanos y menestrales que representa el 53\% de las regidurías, seguidos a distancia por los comerciantes y profesionales liberales con un $20 \%$ cada uno y los fabricantes con el 7\%. Unos porcentajes muy parecidos a los de los periodos absolutistas anterior i posterior, con la salvedad de que la presencia de los menestrales era ligeramente superior en los ayuntamientos absolutistas (59\%); los profesionales liberales, fabricantes y comerciantes ligeramente inferior (34\% en total). Quizás, el aspecto más destacado sea que en los ayuntamientos constitucionales desaparecen los hacendados y los campesinos que, conjuntamente, sumaban el $6 \%$ del total de regidores en los periodos absolutistas ${ }^{9}$.

Que un considerable número de ayuntamientos catalanes escaparon al control liberal nos lo da a entender de forma clara la circular del jefe político de Catalunya en la que se quejaba de que «en vano será que el Gobierno dicte providencias de utilidad y conveniencia pública, si los Alcaldes y Ayuntamientos constitucionales no cuidan de publicarlas y cumplirlas, con el zelo y rapidez convenientes ${ }^{10}$. Todo parece indicar que, como había denunciado Manuel E. Gorostiza: «en tanto que los liberales se afanaban en asegurar una buena representación nacional, los serviles cuidaron solo en preparar una administración municipal que favoreciese más inmediatamente la seducción propuesta» ${ }^{11}$. Esto nos confirma que tanto el liberalismo como el realismo tenían una base popular importante, ya que, desde las guerras contra los franceses, la movilización del pueblo se había hecho imprescindible para dirimir el conflicto político entre revolución y contrarrevolución. 
Tanto en las zonas de más influencia liberal como en las de más influencia realista se produjo una importante renovación del personal político municipal. En el caso del Penedès, dos de cada tres regidores del Trienio Liberal no lo habían sido antes, ni lo serán posteriormente en los ayuntamientos absolutistas. Con todo, uno de cada tres regidores y alcaldes del Trienio Liberal habían ocupado u ocuparían posteriormente cargos municipales: un 20\% de estos regidores lo habían sido entre 1814 y 1819, el 9\% lo serían entre 1823-1833 y el 6\% ocuparían cargos municipales en los periodos absolutistas y en el constitucionalista. Algo parecido sucede en los ayuntamientos de Sarrià (2 245 h.) y L'Aleixar $(680 \text { h. })^{12}$.

En el caso de Reus, el porcentaje de regidores durante el Trienio que no lo habían sido ni serán regidores en los ayuntamientos absolutistas es de cerca del 75\%, eso significa una importante renovación del personal político local: tres de cada cuatro regidores eran nuevos. Tan solo un $16 \%$ de los regidores lo habían sido anteriormente y un $6 \%$ lo serían después, y solo un $4 \%$ lo serían en los tres períodos estudiados. Es importante destacar que las personas que mantienen esta continuidad pertenecen siempre a las clases acomodadas locales, especialmente comerciantes y hacendados. En cambio, la continuidad es casi nula entre las clases populares. En la ciudad de Vic, Clara Furriols también constata que «algunos de los miembros del Ayuntamiento absolutista continuaron formando parte del gobierno municipal durante la etapa constitucional» $\mathrm{y}$ que esta continuidad se dio siempre entre los hacendados. A la vez que, durante el Trienio, se abrieron paso en el Ayuntamiento «la clase media y también los menestrales» «los nobles dejaron de formar parte» ${ }^{13}$. En Manresa, la restauración del absolutismo en 1823 puso fin «al avance del grupo burgués en la gestión municipal, que volvió a quedar en manos de los grupos dominantes tradicionales ${ }^{14}$.

En las ciudades de Barcelona, Girona, Lleida, Manresa y Vic y en las villas y pueblos de Sarrià, l'Hospitalet de Llobregat, Sant Cugat del Vallès y en los municipios del Camp de Tarragona, se obtienen porcentajes de continuidad de entre el $33 \%$ y el $50 \%$ entre los regidores de los ayuntamientos absolutistas y los constitucionales durante el periodo 1814-1833. La continuidad en los cargos municipales fue más elevada en las zonas dominadas por los realistas, como Solsona, donde de los 21 regidores del Trienio, un $30 \%$ lo habían sido antes, un $52 \%$ lo serán posteriormente y un $22 \%$ se habrían mantenido en los ayuntamientos desde 1814 y hasta 1830, independientemente del régimen político dominante ${ }^{15}$. ayuntamientos los mismos apellidos, que los frecuentaban», aunque, «allí donde existía una cierta burguesía local afianza definitivamente su acceso, incluso predominio en la municipalidad» (San Sebastián, Tolosa, Éibar, Elgoibar, Vergara, Villafranca, Oyarzun e Irún), mientras que «en el resto de la provincia, la tradición perdura» ${ }^{16}$. Y lo mismo sucede en la región murciana: «el advenimiento del nuevo régimen no supuso una mutación profunda de las clases dirigentes a escala local», porque «las familias de la oligarquía siguieron concentrando la riqueza y el poder» ${ }^{17}$.

En Andalucía se da también la continuidad de los grupos sociales en el poder político local, pero también aparecen nuevos grupos surgidos durante el proceso de la revolución liberal: «No es la misma oligarquía la que sigue ocupando y controlando el aparato político local pero tampoco podemos afirmar con rotundidad que se trate de un segmento social totalmente nuevo surgido de la Revolución liberal $»^{18}$. En el caso jerezano la ruptura es total y «se da una importante renovación de la élite política local, 
en el estricto plano de los individuos. [...] Sin embargo, en el plano sociológico no se produce tal corte, porque los regidores liberales y absolutistas comparten la misma extracción social. [...] Unos y otros pertenecen a la misma élite de poder que venía controlando la vida municipal desde años anteriores» ${ }^{19}$.

En Zaragoza, Pedro Rújula ha constatado que se produce una importante renovación de los cargos municipales (11 de 14) y que los colectivos que aumentaban su presencia en el consistorio eran los comerciantes y artesanos, mientras que los nobles y los hacendados la disminuían ${ }^{20}$. En cambio, en Castellón de la Plana un $45 \%$ de los regidores del Trienio ya habían sido regidores anteriormente ${ }^{21}$. También en Soria, Toledo y en Lugo se registran importantes continuidades en el poder político local ${ }^{22}$. Lo mismo pasó en los principales ayuntamientos de Asturias y, en cambio, se registró más continuidad en otras ciudades como Salamanca ${ }^{23}$. Cambio y continuidad también caracterizan muchas municipios franceses, sobre todo rurales, durante el período revolucionario i post revolucionario ${ }^{24}$.

\section{A modo de conclusión}

41 Los ayuntamientos constitucionales fueron una pieza clave de la vida política durante el Trienio Liberal y en ellos se materializó el doble conflicto entre liberales y realistas, por una parte, y entre moderados y exaltados, por la otra. Pero, a pesar de estos conflictos y del marco legislativo que los hacía dependientes de las diputaciones y del Jefe político, los ayuntamientos desarrollaron una gran labor en campos como la educación, la sanidad, la beneficencia, el fomento económico y la milicia nacional ${ }^{1}$.

La participación electoral municipal durante el Trienio Liberal en Cataluña se situó entre el $10 \%$ y el $50 \%$ de los vecinos que podían hacerlo. Una horquilla entre la cual se encuentran la mayoría de los municipios españoles. La participación fue más alta en los municipios donde la división política (entre liberales y realistas o entre liberales moderados y exaltados) o las rivalidades históricas entre bandos familiares locales que ahora se rencarnaban en rivalidades políticas eran más profundas. En cualquier caso, debemos ponderar estos porcentajes de participación electoral en el marco histórico, ya que era la segunda vez y, en algunos casos, la primera, que se llamaba a los vecinos a participar en la vida política local para elegir a los electores y a los regidores. No era esta una especificidad española, sino que en Francia sucedía algo parecido².

En los ayuntamientos de pueblos, villas y ciudades catalanas y españolas durante el Trienio Liberal, destaca el importante papel que jugaron los hacendados y las clases medias urbanas (comerciantes, fabricantes y profesionales liberales) que ocuparon la mitad de las regidorías y alcaldías. Podemos afirmar, pues, que en Catalunya los ayuntamientos constitucionales del Trienio fueron dominados y/o controlados por las clases acomodadas locales, variando los colectivos socioeconómicos concretos en función de las diferentes realidades de cada municipio ${ }^{3}$. De la misma manera que entre los electores parroquiales que elegían directamente los vecinos hay un claro predominio de las clases medias (51\%) y de las acomodadas (33\%). En este sentido, se puede afirmar que los ayuntamientos constitucionales del Trienio sacaron a la nobleza de los ayuntamientos; redujeron el peso de algunos sectores populares (artesanos y menestrales, tejedores y pequeños campesinos); y aumentaron la presencia de las clases acomodadas y medias locales (hacendados, propietarios, comerciantes, fabricantes y profesionales liberales). 
Por otro lado, podemos concluir que cambio y continuidad se dan en partes iguales en los ayuntamientos constitucionales del Trienio Liberal (1820-1823) respecto de los absolutistas anteriores (1814-1819) y posteriores (1824-1830). La renovación municipal durante el Trienio liberal se situó entre el $33 \%$ y el $75 \%$ de los regidores, dependiendo de los municipios.

En los municipios más grandes y con una economía más moderna y donde la cultura política liberal estaba más implantada se produjo una renovación más amplia del poder político local; y en los municipios pequeños y en aquellos donde la cultura política realista estaba más enraizada se produjo una menor renovación. Las continuidades con los períodos absolutistas anterior y posterior se redujo a una media del $33 \%$, siendo más acentuada entre 1814-1819 y 1820-1823 (uno de cada cuatro regidores), que no entre 1820-1823 y 1824-1830 (uno de cada diez regidores), debido, fundamentalmente, a la brutal represión desatada por el absolutismo fernandino ${ }^{4}$.

El Trienio Liberal significó una ruptura importante, aunque no total con el poder político municipal del período absolutista anterior. Con todo y a pesar de los cambios, hay determinadas familias acomodadas locales que consiguen mantener su poder político gracias a su poder económico y a su capacidad de acomodación a los cambios políticos y a las estrategias familiares. Estas personas representan, aproximadamente, un $10 \%$ de los regidores del periodo 1814-1833. Es lo que Jessenne en el caso francés llama «raíces del poder» entre las que destacan las redes relacionales y de parentesco ${ }^{5}$

\section{NOTAS}

1. Concepción de Castro, La Revolución Liberal y los municipios españoles, Madrid, Alianza, 1979; Javier García Fernández, El origen del municipio constitucional: autonomía y centralización en Francia y España, Madrid, IEAL, 1983; Ricardo Gómez Rivero, Las elecciones municipales en el Trienio Liberal, Madrid, Boletín Oficial del Estado, 2015; VVAA, El municipio constitucional, Madrid, INAP, 2003; Clara Furriols, El municipi constitucional de Vic (1820-1823), tesis doctoral inédita, URV, 2013; y Adolfo Posada, Evolución legislativa del régimen local de España (1812-1909), Madrid, IEAL, 1982 [1910]. Para el Trienio remitimos a Alberto Gil Novales, Las sociedades patrióticas (1820-1823), Madrid, Tecnos 1975 y El Trienio liberal, Madrid, Siglo XXI, 1980; y para Catalunya Ramon Arnabat, La revolución de 1820 i el Trienni liberal a Catalunya, Vic, Eumo, 2001.

2. Adolfo Posada, Evolución legislativa del régimen local español en España, Madrid, IEAL, 1982 [1910], p. 116-117. Ver también Francisco Carantoña, «Liberalismo y administración territorial. Los poderes local y provincial en el sistema constitucional de Cádiz», Alberto Gil Novales (ed.), La Revolución Liberal, Madrid, Ediciones del Orto, 2001, p. 135-157.

3. Josep Castellar, Instrucción Provisional para facilitar las relaciones de los pueblos de esta provincia con el Gobierno Superior Político de la misma [Barcelona, 16 de mayo de 1820].

4. A las Cortes, Barcelona, Imprenta del Gobierno, 1821 (Arxiu de la Diputació de Barcelona -ADB-, legajo 20, expediente 9).

5. Capítulo III, artículo 183 del Decreto de 3 de febrero de 1823. Ver, José SánchezArchilla, «Los antecedentes del Gobernador Civil: El Jefe político bajo la Constitución de 1812», Arturo Cajal Valero (ed.), El Gobernador Civil en la política y en la Administración de 
la España contemporánea, Madrid, Ministerio del Interior, 1997, p. 159-242; Mª Ángeles Hijano, «La pérdida del poder político en los ayuntamientos tras la revolución liberal», Pablo Fernández Albadalejo y Margarita Ortega López (eds.), Antiguo Régimen y liberalismo. 3. Política y Cultura, Madrid, Alianza Editorial, 1995, p. 163-173 y «Alcaldes constitucionales y Jefes político: bases del régimen local en la primera etapa del constitucionalismo», Revista de Estudios Políticos, 93, Madrid, 1996, p. 259-271; Manel Risques, El govern civil de Barcelona al segle XIX, Barcelona, Abadia de Montserrat, 1995, p. 173-183; y Antoni Jordà, Orígens de la Diputació de Tarragona (1822-1840). Divisió territorial, organització institucional $i$ relacions amb els ajuntaments, Tarragona, Diputació de Tarragona, 2008.

6. M. Risques, El govern civil..., op. cit., p. 170-171.

7. Archivo del Congreso de Diputados (ACD), legajo 82, expediente 5.

8. Coloqui entre un rector y un pagès anomenat Macari, Barcelona, Imprenta Dorca, 1820.

1. José de Churruca, Reflexiones a las Cortes sobre la ley de elecciones de ayuntamientos, Madrid, Imprenta de Álvarez, 1821, p. 23.

2. Joaquín Varela Suances, «Propiedad, ciudadanía y sufragio en el constitucionalismo español (1810-1845)», Historia Constitucional, nº 6, 2005, p. 105-123; Leyre Burguera y Carlos Vidal, «Sistema electoral en la constitución de Cádiz», Revista de derecho político, n.․ 83, 2012, p. 43-64; Margarita Caballero, «El derecho de representación: sufragio y leyes electorales», Ayer, no 34, 1999, p. 41-63; y R. Gómez Rivero, Las elecciones municipales..., op. cit., p. 163-204.

3. Carta del alcalde de Pals (Girona) con fecha de 10 de abril de 1820 (Arxiu Històric de la Ciutat de Girona -AHCG- Caja I.1.2.5 Ajuntament, legajo 1 (1820).

4. Discurso patriótico a los habitantes de Cataluña sobre las Juntas Electorales de Parroquia, Barcelona, Impremta de Piferrer, 1820.

5. Para Catalunya ver ADB, legajo 14, expediente 18; y para el conjunto de la monarquía ver Archivo Histórico Nacional -AHN- Estado, legajo 134.

6. Diario de Barcelona, $\mathrm{n}^{\circ}$ 81, 21 de marzo de 1820, p. 645-646.

1. Los datos en Actes municipals, Reus 1819-1820, fol.106-108, sesión de 2 de diciembre de 1820 y Actes municipals, Reus 1821-1822, sesión de 9 de diciembre de 1821 (Arxiu Històric Municipal de Reus -AHMR-).

2. Los datos en Acuerdos, Tarragona 1820, sesiones de 11 de marzo, 1 y 10 de diciembre de 1820 y doc.87 (Arxiu Històric Municipal de Tarragona- AHMT-).

3. Bando del Ayuntamiento de Tarragona con fecha de 24 de noviembre de 1822 (Acuerdos, Tarragona 1822, doc. 807).

4. Actes. Granollers. 1820-1823, sesiones de diciembre de 1820 y de diciembre de 1821 (ADB, legajo 81, expediente 8).

5. Arxiu Històric de la Paeria de Lleida (AHPL), caja 1.413.

1. Ramon Arnabat, Liberals i Reialistes. El Trienni Liberal al Penedès (1820-1823), Vilafranca del Penedès, Institut d'Estudis Penedesencs, 2004, p. 46-52. Siempre que nos refiramos al Penedès en este texto fundamentamos nuestros análisis en esta fuente. La muestra que servía de base al estudio recogía datos de 406 alcaldes y regidores entre 1814-1830 (185 entre 1820 y 1823) de diez municipios del Penedès con una población total de 32.565 habitantes.

2. Elaboración propia a partir de los datos que facilitan Josep Clara, «Sobre la Girona Constitucional (1820-1823)», Annals de l'Institut d'Estudis Gironins, XXVIII, Girona, 1984, p. 357-390; Mònica Bosch, «Girona capital d'Hisendats», Lluís Costa (dir), Història de Girona. Girona, CCG Edicions, 2006, p. 381-389; Antoni Simón Tarrés, La crisis del Antiguo Régimen en Girona, Bellaterra, UAB, 1985, p. 197-208; Mònica Bosch y Joaquim M. Puigvert (eds.), Girona en época contemporània, 1800-1939, Girona, Ajuntament de Girona, 2016. 
3. Elaboración propia a partir de los datos que facilita Francesc Costa, Mataró revolucionari. Contra el Rei i la Religió, Mataró, La Rambla, 1989, p. 16-20 y Mataró al segle XIX, Barcelona, Dalmau, 1993, p. 63.

4. Los datos en el AHPL, caja 1.413 y en el Diario de Barcelona de 2 de enero de 1823, p. 14. Ver también Antonio Sánchez Carcelén, «Els polítics de Lleida al Trienni Liberal (1820-1823», HMiC. Historia Moderna y Contemporánea, 4, Bellaterra, Universitat Autònoma de Barcelona, 2006, p. 1-24; Manuel Lladonosa, Carlins i liberals a Lleida (1833-1840), Lleida, Pagès, 1993, p. 114-136; Quintí Casals, Polítics de Lleida. El poder local i les seves mutacions a través del temps (1716-1868), Lleida, Universitat de Lleida, 2002 y «Conseqüències de la lluita pel poder local en la primera meitat del segle XIX en la formació de la identitat social de la Lleida contemporània», IV Congrés Internacional d'Història de Catalunya. El cor urbà dels conflictes, Barcelona, L'Avenç, 1999, p. 310-320, «Absolutismo y revolución liberal en Lleida (1716-1868). La lucha social por la toma de la Paeria», Alberto Gil Novales (ed.), La Revolución Liberal, Madrid, Ediciones del Orto, 2001, p. 65-96.

5. Marcel Poblet, «Societat i política a l'Hospitalet. Els períodes 1820-1823, 1840-1843 i 1854-1856», Identitats, nº 4/5, 1990, p. 52-72.

6. Ferran Ayala, «L'ajuntament de Sant Cugat a mitjan segle XIX: polítics, propietaris i parents», Gausac, no 12, 1998, p. 25-36.

7. Elaboración propia a partir de los datos que facilita Carles Gelabertó, Revolució liberal i guerra civil a la marina de la Selva, Mataró, Caixa Laietana, 1991, p. 39-41.

8. Actes. Esparreguera. 1822, sesión de 8 de diciembre de 1822 (ADB, legajo 81, expediente 7).

9. Maties Ramisa, «Poder local a la ciutat de Vic durant el primer terç del segle XIX», II Congrés Internacional d'Història Local de Catalunya. Formes i relacions del poder local a l'època contemporània, Barcelona, L'Avenç, 1995, p. 293-302; y C. Furriols, El municipi constitucional..., op. cit., p. 287-291.

10. Actes. Granollers. 1820-1823.

11. Ramon Arnabat, Verds i blancs. El trienni liberal a Reus i al Baix Camp (1820-1823), Reus, Associació d'Estudis Reusencs, 2002, p. 43-51.

12. Acuerdos Tarragona 1820-1823. Ver también $M^{a}$ Antònia Ferrer Bosch, La ciutat de Tarragona durant el Trienni liberal (1820-1823), 3 vol., tesis doctoral inédita, Universitat de Barcelona, 1980.

13. Ramon Arnabat, «La revolución liberal a Barcelona. Política de classes i classes de política», Barcelona quaderns d'història, no 10, 2004, p. 11-58 y «El govern de la ciutat de Barcelona durant el Trienni liberal (1820-1823) i la seva comparació amb el govern local a Catalunya», Joan Roca (coord.), El municipi de Barcelona $i$ els combats pel govern de la ciutat, Barcelona, Proa, 1997, p. 109-122; Jordi Roca, La Barcelona revolucionària i liberal: exaltats, milicians $i$ conspiradors, Barcelona, Fundació Noguera, 2011; Eliseu Toscas, «Elements de continuïtat política local a la Barcelona del primer terç del segle XIX», Afers, no 15, 1993, p. 163-174; y Eliseu Toscas i Ferran Ayala, «Aspectes del poder polític local a la Barcelona del Trienni 1820-1823», Gausac, nº 7, 1995, p. 39-43.

14. E. Toscas y F. Ayala, «Aspectes ...», op. cit., p. 41-42.

15. María Cruz Romeo, Entre el orden y la revolución, Alacant, Institut de Cultura Joan GilAlbert, p. 106-107, 149 y 204-206.

16. Otília Martí, Un liberalismo de clases medias (1808-1858), Castelló, Diputació de Castelló, p. 148-162.

17. Valentí Valenciano, El camí de Mallorca a la Modernitat: Reacció i revolució a Mallorca, 1814-1823, Palma de Mallorca, Illa edicions, 2016, p. 68-70. 
18. Vicente Fernández Benítez, Burguesía y revolución liberal: Santander, 1812-1840, Santander, Librería Estudio, 1989, p. 70-72; y Jesús J. Alonso, Problemática agraria y solución burguesa. Logroño, 1750-1833, Logroño, Gobierno de la Rioja, 1991, p. 216-224.

19. Claudio Calles, «La revolución de 1820 en Salamanca», Salamanca. Revista de Estudios, ํㅡ 46, Salamanca, 2001, p. 69-114.

20. A. Fernández González, «Los grupos de poder local en Galicia, 1750-1850», Noticiario de Historia Agraria, no 9, 1995, p. 129-153 (p. 150 para la cita).

21. Juan S. Jiménez, Francisca Muñoz y Francisco Díez, «El Trienio constitucional en la campiña de Córdoba: el caso de Ferrán Núñez», Trienio. Ilustración y liberalismo, nㅡㄴ 13, 1989, p. 69-118; y Ángel García Sanz, «Cambio institucional y actitudes políticas en Segovia durante el Trienio Liberal (1820-1823)», Estudios Segovianos, nº XXX, 1978-1988, p. 7-35.

22. Juan F. Fuentes, «La formación de la clase política del liberalismo español: análisis de los cargos públicos del Trienio Liberal», Historia Constitucional. Revista electrónica de Historia Constitucional, $\mathrm{n}^{\circ}$ 3, 2002, p.8.

23. Jean-Pierre Jessenne, Pouvoir au village et Révolution. Artois 1760-1848, París, PU de Lille, 1987, p. 49-137 y «Continuités et ruptures dans la détention des fonctions locales en Artois (1789-1800)», M. Michel Vovelle (ed.), La Révolution Française et le monde rural, París, Editions de CTHS, 1989, p. 397-412; Roger Dupuy (dir.), Pouvoir local et Révolution. 1780-1850, Rennes, Presses Universitaires de Rennes, 1999; y Eliseu Toscas, «Los estudios sobre el poder local en la Francia rural (siglos.XVIIIXIX). Un comentario bibliográfico», Noticiario de Historia Agraria, ํㅡㄹ 2, 1991, p. 114-120.

24. J-P. Jessenne, Pouvoir..., op. cit., p. 131-137. En el mismo sentido Gilbert Schneider, «Le personnel dirigeant du district de Rouen (1790-1795)» y Bernard Bodinier, «Dix ans de révolution pour que tout reste pareil: le corps municipal de Louviers (1789-1799)», Christine Le Bozec y Eric Wauters (eds.), Pour la Révolution Française. En hommage à Claude Mazauric, Rouen, PURH, 1998, p. 163-176; M. Vovelle (ed.), La Révolution..., op. cit., p. 343-455.

1. R. Arnabat, «La revolución liberal...», op. cit., p. 18-24.

2. Actes municipals de Reus, vol. 1819-1820, 1821-1824.

3. Acuerdos Tarragona 1820-1823.

4. J. Clara, «Sobre...», op. cit., p. 364-371.

5. AHPL, caja 1413.

6. Actes. Granollers. 1820-1823.

7. AHCG, I.1.2.5 Ajuntament, legajo 1 (1820).

8. Actes. Caldes de Montbui. 1820-1822, sesión de 30 de abril de 1820.

1. R. Arnabat, Liberals..., op. cit., p. 55.

2. J. Clara, «Sobre...», op. cit., p. 364-371.

1. R. Arnabat, «El govern...», op. cit., p. 111-122.

2. Actes municipals de Reus, vol.1817-1818, 1819-1820, 1821-1824 y 1825-1827.

3. M. Bosch, «Girona...», op. cit., p. 248. Jacinto Saiz, El Trienio Constitucional. Su reflejo en Gerona, tesis de licenciatura inédita, UAB, 1974, p. 38, enfatiza la continuidad del personal político local en los pequeños pueblos del corregimiento de Girona.

4. Q. Casals, «Absolutismo y revolución liberal...», op. cit., p. 65-84.

5. $\mathrm{M}^{\mathrm{a}}$ C. Romeo, Entre el orden..., op. cit., p. 104-109, 149 y 204-206.

6. O. Martí, Un liberalismo..., op. cit., p. 148-162.

7. R. Arnabat, Liberals..., op. cit., p. 50-52. Para las tierras del Ebro J. R. Vinaixa, La postguerra del francés i la revolta reialista de 1822 a l'Ebre, Barcelona, Columna, 1998, p.106-120 y El Trienni Constitucional al partit de Tortosa (1820-1823), Valls, Cossetània, 2003, p. 59-92. 
8. Núria Sauch, Guerrillers $i$ bàndols civils entre l'Ebre i el Maestrat: la formació d'un país carlista (1808-1844), Barcelona, Abadia de Montserrat, 2004, p. 126-136 y 511-517, «Els aixecaments reialistes a Ulldecona durant el Trienni Liberal (1820-1823)», Rails, nº 13, 1999, p. 45-58 y «La disputa pel control municipal a Ulldecona durant el cinc anys previs al Trienni Liberal (1815-1819)», Rails, № 16, 2000, p. 44-53.

9. Arxiu Històric Comarcal de Solsona (AHCS), legajo 99, expediente 33; y Ramon Arnabat, «La lluita entre liberals i reialistes a Solsona i el Solsonès durant el Trienni liberal (1820-1823)», Antoni Segura (dir.), El Carlisme i la dona. V Seminari sobre el Carlisme, Barcelona, Fundació Francesc Ribalta, 1999, p. 85-104.

10. Con fecha de 26 de setembre de 1821 (ADB).

11. Manuel E. Gorostiza, Cataluña a fines de Julio de 1822, o sea rápida ojeada sobre el origen, progresos, proyectos y recursos de la facción liberticida en sus cuatro provincias, Madrid, Imprenta de Eusebio Alvarez, 1822, p. 29.

12. Eliseu Toscas, L'Estat $i$ els poders locals a la Catalunya del segle XIX. Una visió des de Sarrià (1780-1860), Barcelona, Abadia de Montserrat, 1997, p. 165-241; y Pere Anguera, «Economia i societat en un poble del comtat de Prades a la crisi de l'Antic Règim: l'Aleixar 1815-1824», Quaderns d'Història Contemporània, nº 9, 1991, p. 91-109.

13. C. Furriols, El municipi constitucional..., op. cit., p. 506-507.

14. Àngels Solà, Ramon Vila y Lluís Virós, «La formación de nuevas élites locales (1780-1824). Un ejemplo de la Cataluña interior», Ricardo Robledo, Irene Castells y M ${ }^{a}$ Cruz Romeo (eds.), Orígenes del liberalismo. Universidad, política, economía, Salamanca, Ediciones Universidad de Salamanca, 2002.

15. R. Arnabat, «La lluita...», op. cit., p. 85-104.

16. Félix Llanos, El Trienio Liberal en Guipúzcoa (1820-1823), San Sebastián, Universidad de Deusto, 1998, p. 112-137, 203-231 y 338-352; p. 135 para la cita. Ver también, Fernando Martínez Rueda, Los poderes locales en Vizcaya. Del Antiguo Régimen a la Revolución Liberal, 1700-1853, Bilbao, Universidad del País Vasco, 1994, p. 235-310; Coro Rubio, Fueros y Constitución: la lucha por el control del poder (País Vasco, 1808-1868), Bilbao, Universidad del País Vasco, 1997, p. 131-137; J. Víctor Arroyo, Sestao entre la francesada y el Trienio Liberal (1808-1825), Bilbao, Imprenta Amado, 1988, p. 31-51; y M ${ }^{a}$ Teresa Gabarain, «El liberalismo en Rentería», Boletín de la Real Sociedad Bascongada de Amigos del País, n⿳ำ XXXVI-3/4, 1983, p. 627-638.

17. $M^{\mathrm{a}}$ Teresa Pérez Picazo, «De regidor a cacique: las oligarquías municipales murcianas en el siglo XIX», Pegerto Saavedra y Ramón Villares (eds.), Señores y campesinos en la Península Ibérica, siglos XVIII-XX, Barcelona, Crítica, 1991, vol. I, p. 16-37, p. 29-30 para la cita. Mª Teresa Pérez Picazo, «Las transformaciones de la oligarquía murciana en el siglo XIX», Martínez LambertGorges (ed.), Les élites locales et l'État dans l'Espagne Moderne du XVI ${ }^{e}$ au XIX ${ }^{e}$ siècle, París, CNRS, 1993, p. 327-341; $M^{a}$ Teresa Pérez Picazo y Guy Lemeunier, El proceso de modernización de región murciana (siglos XVI-XIX), Murcia, Editora Regional, 1984, p. 250-273; Gregorio Sánchez Romero, Revolución y reacción en el noroeste de la región murciana (1808-1833), Murcia, Real Academia Alfonso X el Sabio, 2001, p. 198-210 y 253-265; y Francisco J. Salmerón, El Trienio Liberal en la provincia de Murcia (1820-1823), Murcia, Editum, 2014.

18. Grupo de Estudios Agrarios, «Transformaciones agrarias y cambios en la funcionalidad de los poderes locales en la Alta Andalucía, 1750-1950», Noticiario de Historia Agraria, no 10, 1995, p. 35-66; Manuel Martínez Martín, Revolución liberal y cambio agrario en la Alta Andalucía, Granada, Universidad de Granada, 1995, p. 309-338; José Ma García León, Cádiz en el Trienio Liberal (1820-1823), Cádiz, Ayuntamiento de Cádiz, 1999; Antonio Guillén, Una aproximación al Trienio Liberal en Almería: la Milicia Nacional Voluntaria, 1820-1823, Almería, Diputación de Almería, 2000; y Isidoro Lara, Jaén (1820-1823). La lucha por la libertad durante el Trienio Liberal, Jaén, Ayuntamiento de Jaén, 1996. 
19. Diego Caro Cancela, «Las élites locales de jerez, entre el absolutismo y el liberalismo (1808-1823)», Diego Caro (ed.), El primer liberalismo en Andalucía (1808-1868), Cádiz, Universidad de Cádiz, 2005, p. 89-126, p. 122 para la cita.

20. Pedro Rújula, Contrarrevolución. Realismo y Carlismo en Aragón y el Maestrazgo, 1820-1840, Zaragoza, Prensa Universitarias de Zaragoza, 1998, p. 61-67.

21. O. Martí, Un liberalismo..., op. cit., p. 150 y 219-227.

22. Margarita Caballero y Carmelo García Encabo, «La revolución de los hacendados: el poder local en Soria en los inicios del liberalismo», Pedro Carasa (ed.), Ayuntamiento, Estado y Sociedad. Los poderes municipales en la España contemporánea, Valladolid, Ayuntamiento de Valladolid, 2000, p. 135-164; Luis Lorente, Revolución liberal y municipalidad. Toledo, 1820-1823, Toledo, Diputación Provincial, 1993; y José Mª Cardesín, «Revolución liberal y poder político: estabilidad y cambio en el mundo rural lucense», José Mํa Donezar y Manuel Pérez Ledesma, Antiguo Régimen y liberalismo. 2. Economía y Sociedad, Madrid, Alianza Editorial, 1995, p. 441-452.

23. Francisco Carantoña, Revolución liberal y crisis de las instituciones tradicionales asturianas (El Principado de Asturias en el Reinado de Fernando VII, 1808-1833), Oviedo, Silverio Cañada editor, 1988, p. 206-211; y C. Calles, «La revolución de 1820...», op. cit., p. 75-85

24. M. Vovelle (dir.), La Révolution Française..., op. cit., p. 381-441.

1. R. Arnabat, La revolució..., p. 63-74 y 111-130; y C. Furriols, El municipi constitucional..., p. 314-510. 2. Melvin Edelstein, «L'Apprentissage de la Citoyenneté: participation Électorale des Campagnards et Citadins (1789-1793)», Michele Vovelle (dir.), L'image de la Révolution Française, Paris, Pergamon Press, 1989, vol. I, p. 15-25; y Georges Fournier, «Entre Vallée de l'Hérault et Vallée de la Garonne: les bastions fermement républicains sous le Directoire», Jean Sentou (ed.), Révolution et contre-révolution dans la France du Midi (1789-1799), Toulouse, Presses universitaires du Mirail, 1991, p. 181-204.

3. Ramon Arnabat, «Élits i control de les institucions polítiques durant el procés de revolució liberal a Catalunya», Conxita Mir y Enric Vicedo (eds.), Control social i quotidianitat, Lleida, Institut d'Estudis Ilerdencs, 2002, p. 281-325.

4. Josep Fontana, De en medio del tiempo. La segunda restauración española. 1823-1834, Barcelona, Crítica, 2006; y Jean-Philippe Luis, L'Utopie réactionnaire: épuration et modernisation de l'État dans l'Espagne de la fin de l'Ancien Régime (1823-1834), Madrid, Casa de Velázquez, 2002.

5. J.P. Jessenne, Le pouvoir..., op. cit., p. 147-263.

\section{RESÚMENES}

Los Ayuntamientos se convirtieron en un elemento clave para la consolidación del sistema constitucional durante el Trienio Liberal (1820-1823) ya que la política se vivía, fundamentalmente, a nivel local, municipal. Durante estos tres años se produjo una profunda transformación de la institución local, tanto por la importante renovación del personal que ocupó alcaldías y regidorías, cómo por las competencias que asumieron. Por otro lado, el ámbito local, con el Ayuntamiento como pieza central, fue escenario de la conflictividad tripolar entre absolutistas, liberales moderados y liberales exaltados.

Les mairies sont devenues un élément clé de la consolidation du système constitutionnel au cours du triennat libéral (1820-1823) puisque la politique était vécue, fondamentalement, au niveau 
local, municipal. Au cours de ces trois années, l'institution locale a été profondément transformée, à la fois par le renouvellement important du personnel qui occupait les mairies et les regidorías et par les compétences qu'ils ont assumées. D'autre part, la région, avec le conseil municipal comme pièce centrale, a été le théâtre du conflit tripolaire entre absolutistes, libéraux modérés et libéraux exaltés.

The Town Halls became a key element for the consolidation of the constitutional system during the Liberal Triennium (1820-1823) since politics was lived, fundamentally, at the local, municipal level. During these three years, there was a profound transformation of the local institution, both due to the important renovation of the staff that occupied mayoralties and regidorías, and due to the competencies they assumed. On the other hand, the local area, with the City Council as a central piece, was the scene of the tripolar conflict between absolutists, moderate liberals and exalted liberals.

\section{ÍNDICE}

Palabras claves: Ayuntamientos constitucionales, Trienio Liberal, liberalismo, realismo, poder local

Keywords: Constitutional councils, Liberal Triennium, liberalism, realism, local power

Mots-clés: Conseils constitutionnels, Trienio liberal, libéralisme, réalisme, pouvoir local

\section{AUTOR}

\section{RAMON ARNABAT MATA}

Universitat Rovira i Virgili - ISOCAC 